\title{
Primary Burns Dressings and cost implications: A UK National Survey results
}

\author{
Joseph Wan ${ }^{1}$, Obi Onyekwelu², Mohammed Eldardiri Ismail Aly ${ }^{2}$ \\ 1. Medical Student, University of Manchester, UK 2. University Hospital of South Manchester
}

\section{INTRODUCTION}

In 2016, 10249 patients attended the specialised burn service for assessment and admission in England and Wales, with the elderly and paediatric populations at particular risk for full thickness and deep dermal burns

Systemic infection and pain are major concerns in managing burn wounds, the use of dressings has evolved over time to achieve the following properties

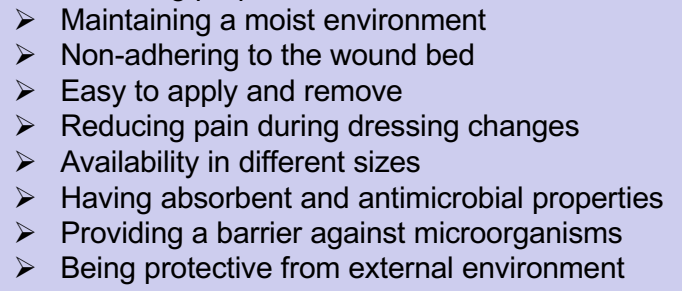

Despite abundant literature demonstrating a wide range of dressings' efficacies and costs, there are no national consensus or guidelines available for primary burns dressings applied following the initial burn debridement. Also, existing guidelines are non-specific regarding which primary dressings to use in various burns depths. The choice of primary dressings must factor in different aspects including appropriate patient care, need for wound inspection and cost to achieve efficient utilisation of resources.

\section{METHODS}

We conducted a telephone survey with 28 major burns services across the UK enquiring about the primary dressing applied to superficial partial thickness; deep partial-mixed depth, deep dermal, and full thickness burns injuries after the initial burn debridement.

The product literature was used to classify the type of dressings accordingly and analyse the cost of the most frequently used ones.

\begin{tabular}{|c|c|c|c|}
\hline Dressing Type & Product & Size & Retail Price \\
\hline \multirow{4}{*}{ Foam, Mesh dressing } & Mepilex & $10 \mathrm{~cm} \times 10 \mathrm{~cm}$ & $£ 2.17^{*}$ \\
\hline & MepilexAg & $10 \mathrm{~cm} \times 10 \mathrm{~cm}$ & £6.12 \\
\hline & Mepitel & $8 \mathrm{~cm} \times 10 \mathrm{~cm}$ & $£ 2.80^{\circ}$ \\
\hline & Acticoat & $10 \mathrm{~cm} \times 10 \mathrm{~cm}$ & f.8.65" \\
\hline Silicone dressing & Adaptic & $12.7 \mathrm{~cm} \times 15 \mathrm{~cm}$ & $£ 4.65 *$ \\
\hline \multirow{4}{*}{ Hydrocolloid Dressing } & Urgotul & $10 \mathrm{~cm} \times 10 \mathrm{~cm}$ & E3.11. \\
\hline & Urgotul SSD & $10 \mathrm{~cm} \times 12 \mathrm{~cm}$ & E3.58. \\
\hline & Jelonet & $10 \mathrm{~cm} \times 10 \mathrm{~cm}$ & $£ 0.41^{\circ}$ \\
\hline & DuoDerm & $10 \mathrm{~cm} \times 10 \mathrm{~cm}$ & E1.33* \\
\hline \multirow{2}{*}{ Topical Ointment } & Flamazine & 50 gram & ⿷3.85. \\
\hline & Flaminal & $50 \mathrm{~g}$ & E25.18" \\
\hline
\end{tabular}

\section{DISCUSSION}

A literature review was conducted, randomised control trials demonstrated benefits in patient outcomes with the use of topical agents in deep dermal and full thickness burns ${ }^{[4]}$. There was also evidence suggesting the cost-effectiveness of hydrocolloid dressings in the treatment of superficial burns $<5 \%$ TBSA [5].

Other factors influence costs such as; frequency of dressing changes, nursing care, and wound inspection requirements. There is a remarkable variation between burns services in the UK regarding these factors.

In the absence of robust evidence in the literature, the choice of primary dressings applied to burn injuries is rarely evidence based. In addition, there is lack of national consensus or guidelines directing the choice of primary dressings recommended for burn wounds of varying depths. Our findings demonstrated a significant variation in the application of primary dressings to partial thickness, deep dermal, mixed depth and full thickness burns with significant cost implications. Level I evidence is required to provide evidence based recommendations for the efficacy of different primary dressings in variable burns wound depth.

\section{CONCLUSION}

There is a significant variation of primary post-debridement dressings used in the UK for the management of burns injuries. Future studies are needed to determine the most cost-effective primary dressing per burn wound depth. This is required in the future as a result of the current austerity environment in the NHS.

\section{RESULTS}

- 19 UK burns units participated in the survey demonstrating a significant variation in the types of dressings used.

- Superficial partial thickness and mixed depth burns were frequently dressed with hydrocolloid dressings. Deep dermal-to-full thickness burns were frequently dressed with topical ointments.

- The use of anti-bacterial dressings to prevent wound infections correlated with increased burn depth.
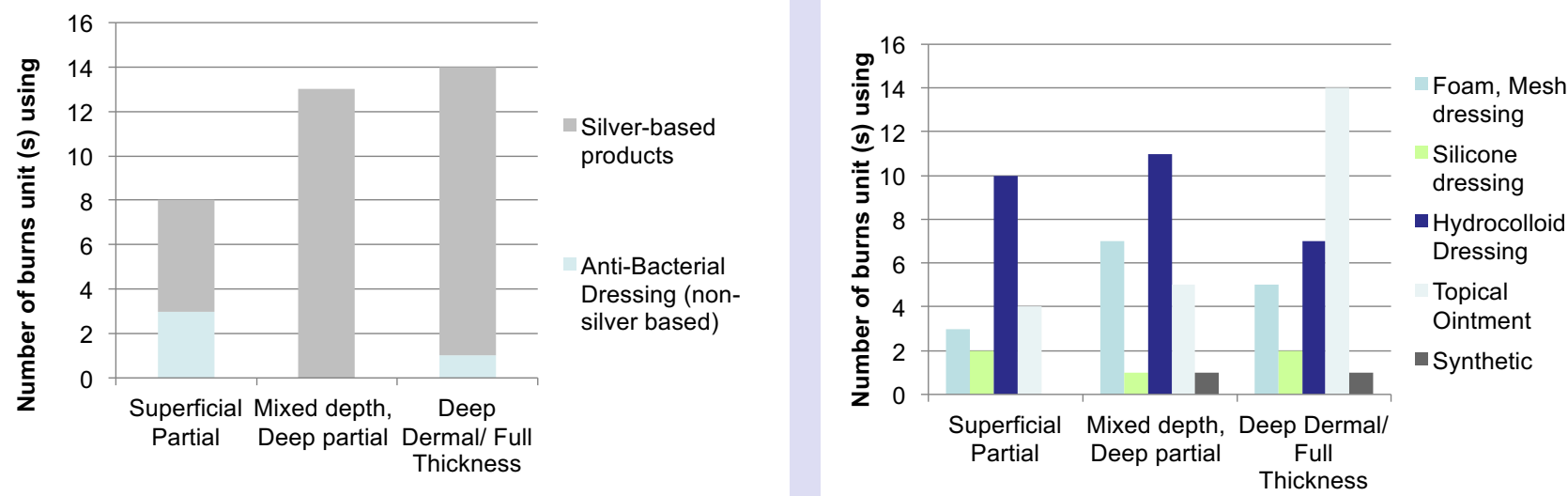